ARTICLE

https://doi.org/10.1038/s41467-019-13449-y

\title{
Sustainable polycarbonate adhesives for dry and aqueous conditions with thermoresponsive properties
}

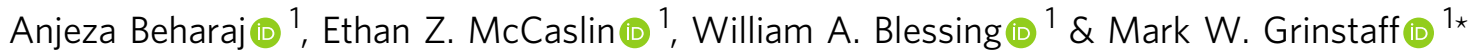

Pressure sensitive adhesives are ubiquitous in commodity products such as tapes, bandages, labels, packaging, and insulation. With single use plastics comprising almost half of yearly plastic production, it is essential that the design, synthesis, and decomposition products of future materials, including polymer adhesives, are within the context of a healthy ecosystem along with comparable or superior performance to conventional materials. Here we show a series of sustainable polymeric adhesives, with an eco-design, that perform in both dry and wet environments. The terpolymerization of propylene oxide, glycidyl butyrate, and $\mathrm{CO}_{2}$, catalyzed by a cobalt salen complex bearing a quaternary ammonium salt, yields the poly (propylene-co-glycidyl butyrate carbonate)s (PPGBC)s. This polymeric adhesive system, composed of environmentally benign building blocks, implements carbon dioxide sequestration techniques, poses minimal environmental hazards, exhibits varied peel strengths from scotch tape to hot-melt wood-glue, and adheres to metal, glass, wood, and Teflon ${ }^{\circledR}$ surfaces. 
P ressure sensitive adhesives (PSAs), soft polymeric materials that adhere to surfaces via Van der Waals interactions under pressure, are primarily composed of acrylic copolymers and polystyrene/isoprene/butadiene based blends ${ }^{1,2}$. These viscoelastic polymers teeter the delicate balance of liquid enough to wet a surface and elastic enough to resist direction of motion. Viscoelastic fine-tuning of bulk polymer properties is accomplished through the addition of tackifiers ${ }^{3,4}$, plasticizers ${ }^{5,6}$, postpolymerization cross-linking 7,8 , or the covalent combination of two or more distinct monomers ${ }^{9-12}$.

Due to their ability to bond dissimilar materials without incompatibility concerns, PSAs are ubiquitous in commodity products such as tapes ${ }^{13,14}$, bandages ${ }^{15}$, labels ${ }^{16}$, household decorations ${ }^{17}$, and packaging ${ }^{18}$. Driven by high demand in consumer goods, the PSA market value is expected to reach $\$ 9.5$ billion by 2024, with environmentally friendly PSAs representing the fastest growing technology segment ${ }^{19}$. Recent advances in this field of adhesion chemistry include biomimetic approaches ${ }^{20}$ such as nanoscale fabrication of the fibrillous geometry found in the adhesive pads of gecko's feet ${ }^{21-24}$, and utilization of dopamine enriched proteins as found in the adhesive footpad of marine mussels ${ }^{25-30}$.

From a polymeric materials design perspective, we are cognizant of the need to consider the environmental impact of a polymer's lifecycle, the polymerization methodology, the composition of the building blocks, and the subsequent polymer breakdown products ${ }^{31-33}$. To this end, we utilize a synthetic pathway pioneered by Inoue et $\mathrm{al}^{34}$ and brought to realization by Coates $^{35}$ and Darensbourg ${ }^{36}$, and a catalyst ligand framework optimized by $\mathrm{Lu}$ et $\mathrm{al}^{37,38}$, in which carbon dioxide and an oxiranyl monomer ${ }^{39-42}$ are activated and linked together to afford a degradable polycarbonate.

Herein, we report a library of environmentally friendly, sustainable, strong, and responsive adhesives composed of carbonate terpolymers. These adhesives exhibit polymer compositional dependences on peel and tack strength, bind to metal, glass, wood, and polytetrafluoroethylene (PTFE), as well as exhibit reversible on-demand adhesion through a temperature trigger in both dry and wet environments. The synthetic approach is highly amenable to many oxiranyl monomers, including those derived from biological feed stocks lowering the dependency on petroleum, and allows for the fine-tuning of the polymer composition and microstructure to attain desired chemical, physical, degradation, and mechanical properties.

\section{Results}

Polycarbonate synthesis. In order to mimic the pendant functionality of current commercial adhesives (Fig. 1a), we synthesized poly(propylene-co-glycidyl butyrate carbonate) (PPGBC) via the terpolymerization of glycidyl butyrate (GB), propylene oxide (PO), and $2.7 \mathrm{MPa}$ of $\mathrm{CO}_{2}$ catalyzed by a salen cobalt complex (2000:1 catalyst loading) at $40^{\circ} \mathrm{C}$ (Fig. 1b, c, and Supplementary Methods). The ester side chain of GB imparts adhesivity through Van der Waals interactions, while PO allows for tighter compaction of polymer chains, raising the glass transition temperature, and polymeric cohesive strength. The monomeric units derived from chain scission of PPGBC are biologically benign ${ }^{43,44}$ and are comprised of glycerol and PO, food additives identified as Generally Recognized as Safe (GRAS) by the FDA, as well as butyric acid, a compound responsible for the characteristic smell of feta cheese ${ }^{45}$, and $\mathrm{CO}_{2}$, an atmospheric gas (Fig. 1d).

Specifically, we synthesized a library of co- and terpolymers with varying monomeric feed ratios of $\mathrm{GB}$ and $\mathrm{PO}$ as shown in Table 1 . The catalyst, $[S, S]-\left[\right.$ SalcyCo $\left.{ }^{\mathrm{III} D N P}\right] / \mathrm{DNP}^{38}$, polymerized PO with high turnover frequency $\left(444 \mathrm{~h}^{-1}\right)$, high polymer selectivity (>99\%), moderate molecular weight $(22 \mathrm{~kg} / \mathrm{mol})$, and low dispersity (1.18). Under the same conditions, the catalyst polymerized GB with lower TOF $\left(77 \mathrm{~h}^{-1}\right)$, lower polymer selectivity $(86 \%)$, lower molecular weight of $(12 \mathrm{~kg} / \mathrm{mol})$, and similar dispersity (1.2). In the controlled and living $\mathrm{CO}_{2} / \mathrm{PO} / \mathrm{GB}$ terpolymerization, increasing the $\mathrm{PO}$ monomer feed concentration led to sequentially higher TOFs compared with GB alone. Similarly, increasing PO monomer feed concentration afforded greater molecular weight polymers and higher polymeric selectivity over the cyclic carbonate.

The glass transition temperature, measured by differential scanning calorimetry (DSC), is $28^{\circ} \mathrm{C}$ and $-7^{\circ} \mathrm{C}$ for PO and GB, respectively. For the terpolymers, as the $\mathrm{GB}$ content increases the glass transition reduces from 0 to $-30^{\circ} \mathrm{C}$. A bimodal distribution of chain length is observed for all polymers by GPC analysis, but dispersities remained low at $\sim 1.2$ (Supplementary Fig. 10). This observable phenomena is due to adventitious water molecules as MALDI-ToF spectroscopy revealed two initiating groups (hydroxyl and dinitrophenoxide) for polymeric chains and one terminating group (hydroxyl) (Supplementary Fig. 8).

Fineman-Ross analysis was undertaken to determine the probabilistic sequence distribution of monomers in the copolymer composition. In order to approximate steady state kinetics, the reactions were stopped at low conversions ( $5 \%)$ and analyzed by ${ }^{1} \mathrm{H}$ NMR (Supplementary Table 1). The Fineman-Ross linearization method revealed a strong correlation $\left(R^{2}=0.9994\right)$ between monomer percentage in the feed and monomer incorporated into the polymer. The monomeric reactivity ratios for $\mathrm{GB}\left(r_{\mathrm{GB}}=k_{11} / k_{12}\right)$ and $\mathrm{PO}\left(r_{\mathrm{PO}}=k_{22} / k_{21}\right)$ are 1.32 and 0.26 , respectively (Fig. 2 ), indicating consecutive incorporation of two GB units is more favored during the terpolymerization. This preference is due to the electron donating effects of the pendant ester of GB, increasing epoxide nucleophilicity over $\mathrm{PO}$, and enabling faster coordination to the catalyst active site. Since the GB monomeric feed strongly resembles GB polymer incorporation at high conversions (Table 1, 60\% conversion), the terpolymer possesses a gradient distribution of PO insertion, with more PO units incorporated toward the end of the chain.

Adhesion measurements. We conducted peel testing to compare the relative adhesive strengths, defined as the force per width required to separate a flexible substrate from a rigid substrate, for all the viscous terpolymers at room temperature (Fig. 3a). Glass slides $\left(\mathrm{SiO}_{2}\right)$ were used as the base substrate, and A4 paper $(2.6 \times$ $8 \mathrm{~cm}$ ), wetted with neat adhesive, was used as the face substrate. Testing was performed on an Instron 5944 series at $180^{\circ}$ peel angle at a rate of $360 \mathrm{~mm} / \mathrm{min}$ following procedures from ASTM D903.

PPGBC-56 exhibits superior adhesion with a peel force of $4.9 \pm$ $0.41 \mathrm{~N} / \mathrm{cm}$ compared with all other terpolymers and similar to Duct$\operatorname{tape}^{\circledR}$ (3M 2929) $(4.1 \pm 0.48 \mathrm{~N} / \mathrm{cm})$. PGBC-100 $(2.6 \pm 0.23 \mathrm{~N} / \mathrm{cm})$ displays a peel strength comparable to Scotch-tape ${ }^{\circledR}$ (3M 810) $(2.1 \pm$ $0.20 \mathrm{~N} / \mathrm{cm}$ ). PPGBC-74 and PPGBC-87, exhibiting low glass transition temperatures (approximately $-30^{\circ} \mathrm{C}$ ), both demonstrate comparably low peel strength of $\sim 0.8 \mathrm{~N} / \mathrm{cm}$ (Fig. 3a), about twice that of a Post-It ${ }^{\circledR}$ note $(\sim 0.4 \mathrm{~N} / \mathrm{cm})$ under the same experimental conditions ${ }^{40}$. All the polymer adhesives cohesively fail due to weaker bulk forces than surface bonding forces.

To assess PPGBC-56's adhesiveness to chemically distinct materials, we performed probe-tack testing on metal, glass, wood, and PTFE, using a DHR-2 rheometer at room temperature. The top $8 \mathrm{~mm}$ diameter steel plate $\left(50.3 \mathrm{~mm}^{2}\right.$ surface area) was lowered at a rate of $100 \mu \mathrm{m} / \mathrm{s}$ unto one of the four adhesive coated substrates with an applied axial force of $50 \mathrm{~N}$. After $5 \mathrm{~s}$ of contact, 
a

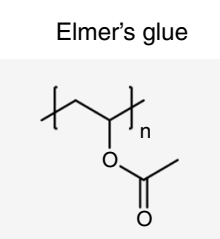

Poly(vinyl acetate)

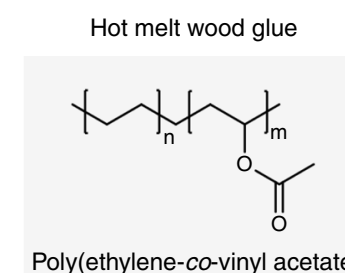

Poly(ethylene-co-vinyl acetate)

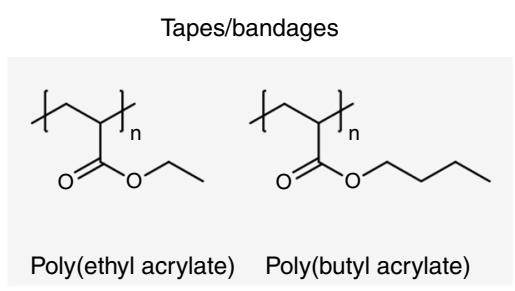

b
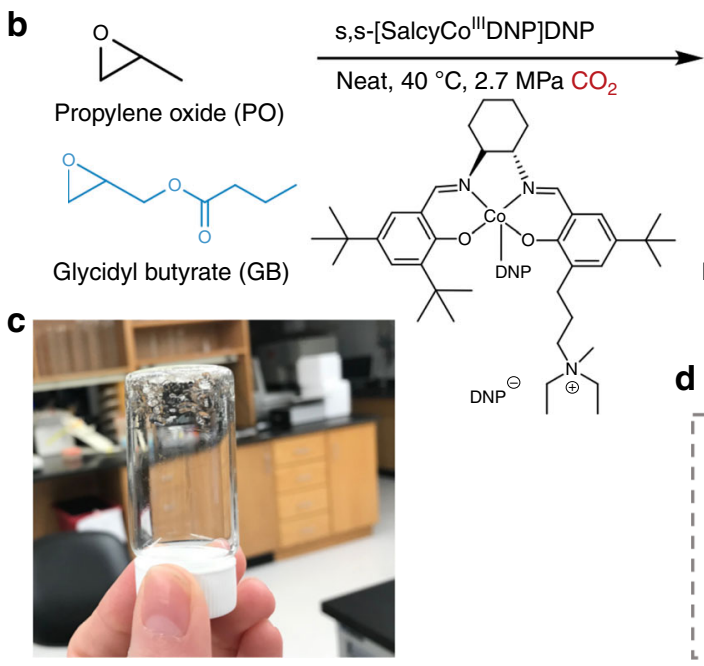<smiles>CCCC(=O)OCC(CC(C)(C)[18OH])OC(=O)OC(C)(C)C(C)(C)COC(=O)OC(C)(C)C</smiles>

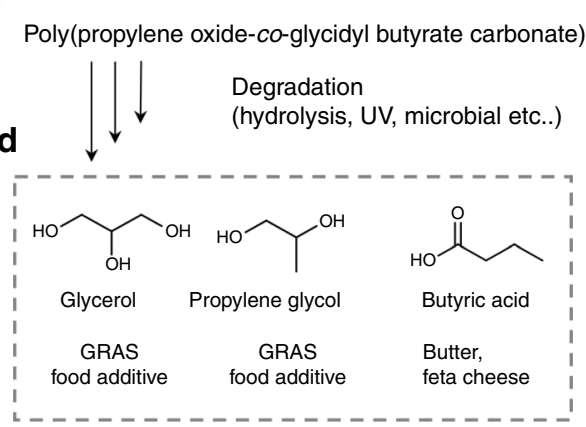

Fig. 1 Chemical structures of commercial adhesives (a), and carbonate terpolymers (b). c Image of PPGBC, a clear highly viscous liquid. d Final products of complete polymer decomposition.

Table 1 Terpolymerization of GB/PO/CO 2 catalyzed by $(S, S)$-[SalcyCo'"'DNP]DNP.

\begin{tabular}{|c|c|c|c|c|c|c|c|}
\hline Entry & $f_{G B: P O^{a}}$ & $F_{\mathrm{GB}: \mathrm{PO}}{ }^{\mathbf{b}}$ & TOF $\left(h^{-1}\right)^{c}$ & Selectivity $(\%)^{d}$ & $\operatorname{Tg}^{\circ} \mathrm{C}^{\mathrm{e}}$ & $\operatorname{Mn}(\mathrm{kg} / \mathrm{mol})^{f}$ & $\oplus\left(M_{w} / M_{n}\right)^{f}$ \\
\hline PGBC-100 & $100: 0$ & $100: 0$ & 74 & 85 & -7 & 12.4 & 1.20 \\
\hline PPGBC-87 & $90: 10$ & $87: 13$ & 78 & 86 & -30 & 6.1 & 1.12 \\
\hline PPGBC-74 & $70: 30$ & $74: 26$ & 129 & 82 & -29 & 6.0 & 1.10 \\
\hline PPGBC-56 & $50: 50$ & $56: 44$ & 144 & 95 & -9 & 8.6 & 1.08 \\
\hline PPGBC-33 & $30: 70$ & $33: 67$ & 158 & 90 & -12 & 13.6 & 1.11 \\
\hline PPGBC-22 & $10: 90$ & $22: 78$ & 225 & 99 & 0 & 9.6 & 1.11 \\
\hline PPC-100 & $0: 100$ & $0: 100$ & 444 & $>99$ & 28 & 22 & 1.18 \\
\hline \multicolumn{8}{|c|}{$\begin{array}{l}\text { The reaction was performed in neat epoxide }(10 \mathrm{mmol}) \text { in a } 15 \mathrm{~mL} \text { autoclave under } 2.7 \mathrm{MPa} \mathrm{CO}_{2} \text { pressure at } 40^{\circ} \mathrm{C} \text { with } 2000: 1 \text { catalyst loading } \\
\text { a Molar ratio of monomer feed } \\
\text { bMolar ratio of monomer incorporation in polymer chain } \\
\text { cTurnover frequency (TOF) = mole of product (polycarbonates)/mol of cat. per hour. Reactions were stopped at } \sim 60 \% \text { conversion } \\
\text { dPercent of polymer formed vs. cyclic carbonate as determined by }{ }^{1} \mathrm{H} \text { NMR } \\
\text { e Determined by DSC analysis } \\
\text { fDetermined by gel permeation chromatography in THF, calibrated with polystyrene standards }\end{array}$} \\
\hline
\end{tabular}

the top steel substrate was pulled apart with a rate of $100 \mu \mathrm{m} / \mathrm{s}$, and the tack strength $\left(S_{\text {tack }}\right)$, defined as the peak of the force curve, was measured. PPGBC-56 possesses a similar tack strength of $\sim 41 \mathrm{~N}$ to metal, wood, and steel (Fig. 3b). A reduced but still substantial tack strength is observed for PTFE of $27 \pm 1.8 \mathrm{~N}$. PPGBC-56 cohesively fails to metal, wood, and steel while adhesively fails to PTFE. The lower adhesive strength is likely due to the weaker Van der Waals forces between the adhesive and PTFE from the high electronegativity of the fluorine atoms.

In order to identify a temperature responsive PSA, we assessed the adhesion energy of all the polymer formulations at 37 and $50{ }^{\circ} \mathrm{C}$, using a metal-on-metal probe-tack testing protocol. Of the formulations, PPGBC-56 exhibits the desired tack profile for bonding at $37^{\circ} \mathrm{C}$ and debonding at $50{ }^{\circ} \mathrm{C}$ (Supplementary Figs. 12 and 13). Specifically, as shown in Fig. $3 c$, the tack strength of PPGBC-56 with $1 \mathrm{~N}$ of applied axial pressure and $5 \mathrm{~s}$ dwell time at $20^{\circ} \mathrm{C}$ is $9.0 \pm 1.8 \mathrm{~N}$ in a dry environment, and the PSA exhibits adhesive failure with debonding occurring at the polymer-metal interface. Raising the temperature to $37^{\circ} \mathrm{C}$ significantly increases the $S_{\text {tack }}$ to $30.4 \pm 5.2 \mathrm{~N}$. At the higher temperature, the polymer flows, spreads across, and wets the metal increasing the surface area of interaction and adherence to the metal rod surface. The interfacial adhesion between the two surfaces increases such that the PSA now fails cohesively (weaker interchain Van der Waals forces), and debonding occurs between the polymer strands. A further increase in temperature to $50{ }^{\circ} \mathrm{C}$ reduces the $S_{\text {tack }}$ to $9.6 \pm$ $1.6 \mathrm{~N}$ and by $100^{\circ} \mathrm{C}$, the tack strength is significantly less and $3.3 \pm 0.2 \mathrm{~N}$. As the temperature rises, interchain Van der Waals forces further weaken due to increased volume and mobility between polymer strands, and the energy required to debond the materials decreases. The same trend is observed with the PPGBC56 in an aqueous environment with diminished tack strength overall (Fig . 3c). 
A material's viscosity directly correlates with its timely ability to wet a surface and subsequently form an adhesive bond. To quantify the relationship between the pressure applied to PPGBC56 and its ability to form a strong adhesive bond, we conducted metal-on-metal tack testing with varying applied axial forces at 20 and $37^{\circ} \mathrm{C}$ using an $8 \mathrm{~mm}$ steel parallel plate geometry. Again, the probe's dwell time was $5 \mathrm{~s}$ and the top plate was pulled apart with a rate of $100 \mu \mathrm{m} / \mathrm{s}$.

At a temperature of $20^{\circ} \mathrm{C}$, a strong correlation between applied axial force and peak tack strength is observed for PPGBC-56
(Fig. 3d). At a low applied force, $0.5 \mathrm{~N}$, the $S_{\text {tack }}$ is $1.49 \pm 0.53 \mathrm{~N}$ and the material exhibits adhesive failure. As the normal force applied increases from 1 to 5 to $20 \mathrm{~N}$, the $S_{\text {tack }}$ then increases from $9.03 \pm 1.83$ to $17.5 \pm 2.51$ to $25.0 \pm 1.31 \mathrm{~N}$. At $50 \mathrm{~N}$ applied axial force, the debonding force is greater than the maximum load cell of the rheometer $(55 \mathrm{~N})$, and thus, the $\mathrm{S}_{\text {tack }}$ is estimated to be $>55 \mathrm{~N}$. At a temperature of $37^{\circ} \mathrm{C}$, a significantly different tack profile is observed. Even $0.5 \mathrm{~N}$ of applied axial force is sufficient to achieve maximum tack strength. As the polymer's viscosity is significantly less at this temperature, with a stronger viscous than
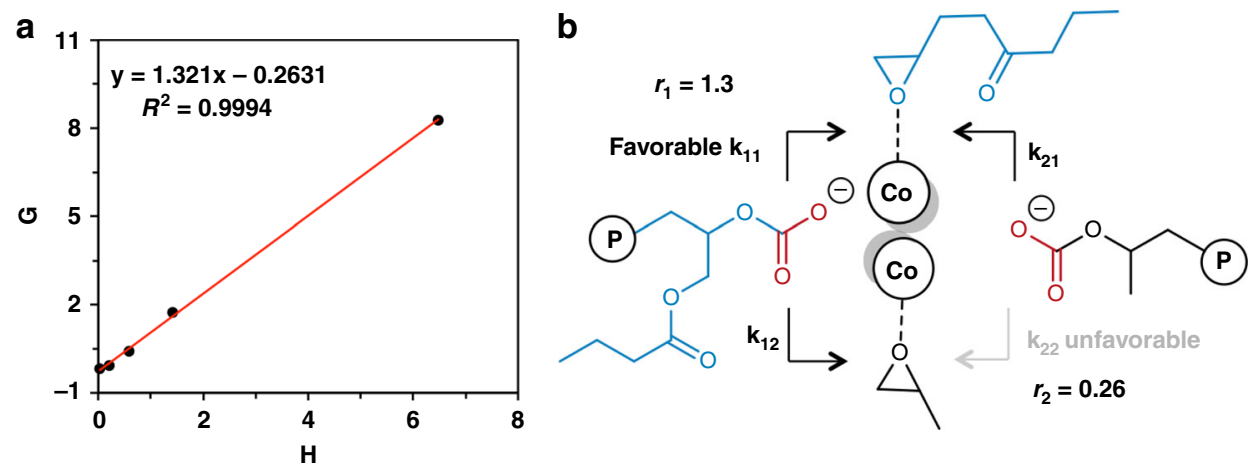

Fig. 2 Probabilistic sequence distribution of monomers in the terpolymer. a Fineman-Ross plot of PPGBC at low conversions. $X=\left[f_{[G B]} / f_{[P O]}, Y=\left[F_{[G B]} /\right.\right.$ $\left.F_{[\mathrm{PO}]}\right], H=Y^{2} / X, G=Y(X-1) / X$. b Schematic of propagation reactions. Source data are provided as a Source Data file and data for Fig. $2 a$ is provided in Supplementary Table 1 .

a

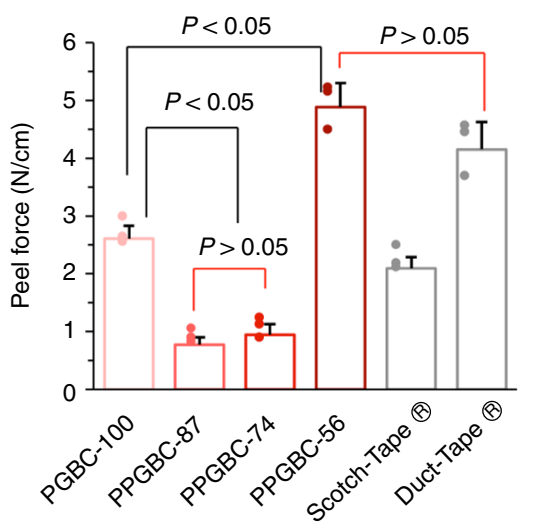

d

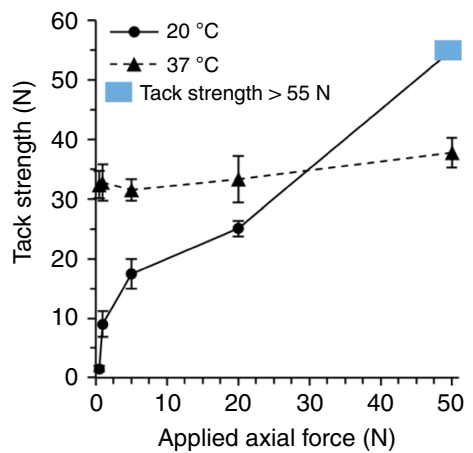

b
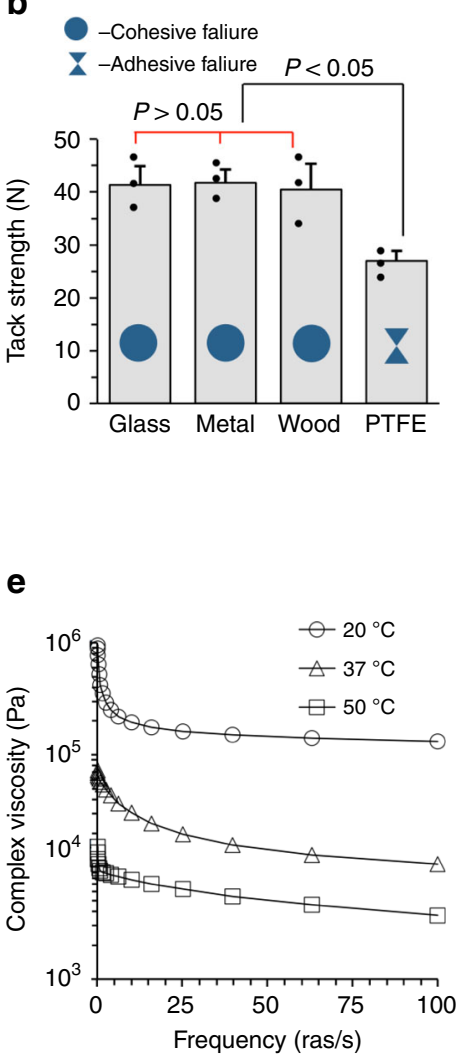

C

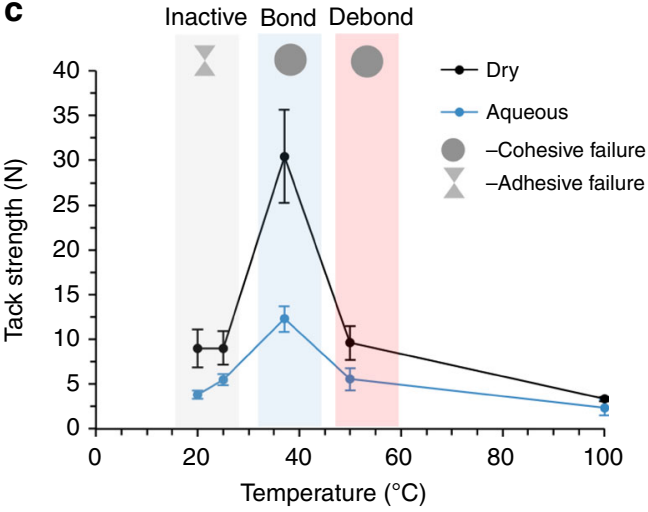

f

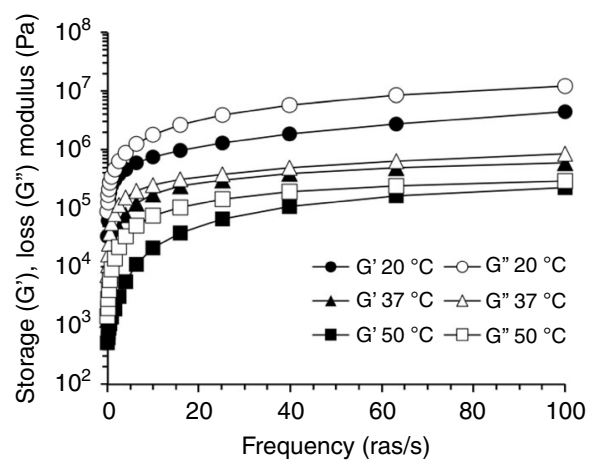

Fig. 3 Adhesive and rheometric properties of terpolymers under various conditions. a Peel testing $\left(180^{\circ}\right)$ at room temperature $\left(22^{\circ} \mathrm{C}\right)$ of viscous poly (propylene-co-glycidyl butyrate carbonate)s and commercial adhesives $(n=3)$. b Tack strength of PPGBC-56 applied to four surfaces at room temperature $(n=3)$. c Tack strength of PPGBC-56 with 1 Newton of applied axial force at different temperatures tested in atmospheric conditions and underwater $(n=$ 3). d Tack Strength vs. different applied axial pressure for PPGBC-56. e Frequency sweep of the complex viscosity ( $\eta$ ) of PPGBC-56 at three different temperature ranges $(n=3)$. f Frequency sweep of the storage $\left(\mathrm{G}^{\prime}\right)$ and loss $\left(\mathrm{G}^{\prime \prime}\right)$ modulus of PPGBC-56 at 20,37 , and $50^{\circ} \mathrm{C}$. Source data are provided as a Source Data file for Figs. 3-d. Error bars indicate mean \pm s.e.m. and all significance testing was conducted using ANOVA. 


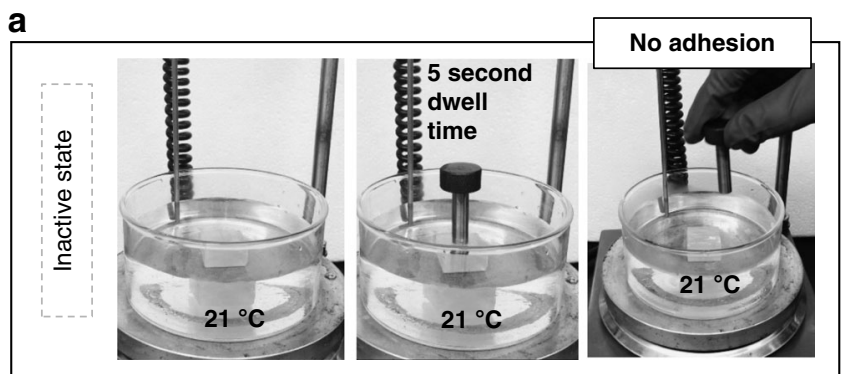

b

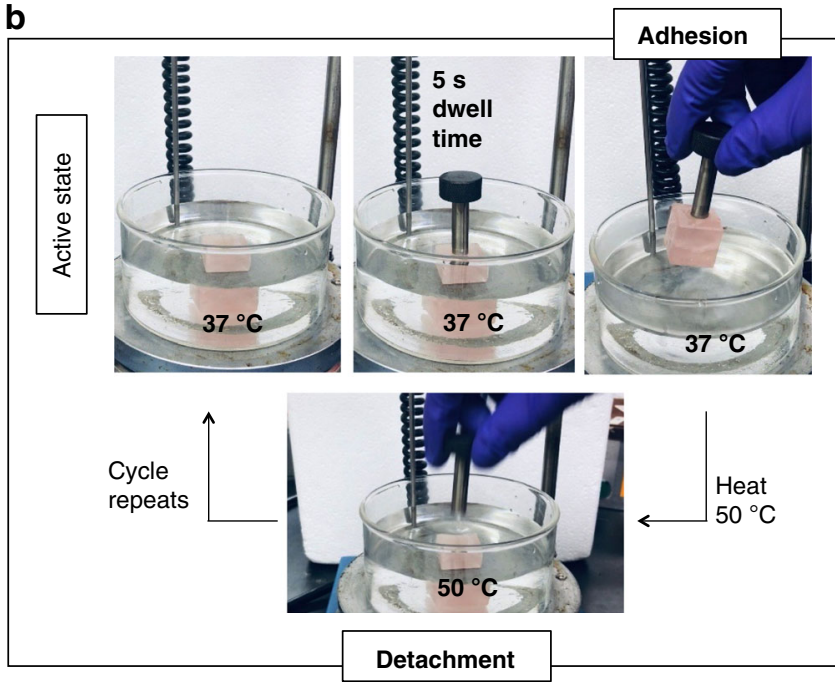

Fig. 4 Adhesive system with thermoresponsive bonding and debonding. a Glass cube $(20 \mathrm{~g})$ coated with PPGBC-56 in DI water with a steel rod ( $35 \mathrm{~g}, 50.3 \mathrm{~mm}^{2}$ surface area) placed on top. At $21^{\circ} \mathrm{C}$, the adhesive is not able to bond to the rod and the adhesive system is inactive. $\mathbf{b}$ At $37^{\circ} \mathrm{C}$, there is sufficient bonding to pick up the glass cube. At $50^{\circ} \mathrm{C}$, the adhesive weakens and detachment of the cube from the rod occurs. Lowering the temperature to $37^{\circ} \mathrm{C}$ repeats the bonding/debonding cycle. Lowering the temperature further to $21^{\circ} \mathrm{C}$ returns the system to the inactive state.

elastic profile (Fig. 3e, f), PPGBC-56 wets and strongly adheres to the probe's surface with minimal applied force (i.e., essentially independent of applied force). An applied axial force of $0.5 \mathrm{~N}$ requires $32.1 \pm 2.3 \mathrm{~N}$ of force to separate the materials. Increasing the applied force to 1,5 , and $20 \mathrm{~N}$ does not change the peak debonding force, which remains $\sim 31 \mathrm{~N}$. At $50 \mathrm{~N}$ of applied axial force, the $\mathrm{S}_{\text {tack }}$ force increases to $37.0 \pm 2.51 \mathrm{~N}$, although bearing no statistical significance.

Utilizing this information we hypothesize that a local temperature change will trigger adhesion by controlling the viscoelastic state of the adhesive underwater. One side of a 1 in. ${ }^{3}$ glass cube $\left(\mathrm{SiO}_{2}, 20 \mathrm{~g}\right)$ was coated with PPGBC-56 and immersed in $21^{\circ} \mathrm{C}$ DI water. A $35 \mathrm{~g}$ metal rod with a surface area of $50.3 \mathrm{~mm}^{2}$ (8 $\mathrm{mm}$ diameter) was gently placed on the adhesive surface, let stand for $5 \mathrm{~s}$, and subsequently removed as shown in Fig. 4a. Under these conditions, the metal rod does not adhere to the glass cube (Supplementary Movie 1). Upon heating the water to $37^{\circ} \mathrm{C}$, the same metal rod was gently placed on the adhesive coated glass cube surface, let stand for $5 \mathrm{~s}$, and removed from the water as shown in Fig. 4b. At this temperature, the metal rod binds to the glass with sufficient force that it is able to pick up and hold the glass cube (Supplementary Movie 2). Raising the temperature of the water to $50^{\circ} \mathrm{C}$ detaches the metal rod from the glass cube (Supplementary Movie 3). At this higher temperature, heating the system expands the polymeric volume, and releases the rod as intermolecular Van der Waals forces wane and cohesive failure detaches the cube. Repeated 37 and $21^{\circ} \mathrm{C}$ cycles of the $\mathrm{rod} /$ cube system display reversibility with the same adhesive coating attaching and detaching the rod. The adhesive detaches through cohesive failure, but remains on each respective surface and polymeric mass is not lost into the water. Replacing PPGBC-56 with duct tape at either 21 or $37^{\circ} \mathrm{C}$ did not result in bonding between the metal rod and glass cube, likely because the applied axial force (weight of the rod) is not sufficient to induce spreading and contact bonding of the adhesive.

Cytotoxicity studies. Although these polycarbonates are composed of relatively benign building blocks, evaluation of toxicity is warranted with the synthesis of new materials, especially, given their potential use in the consumer goods (e.g., food packaging) and medical device areas (e.g., pressure sensitive adhesive). Preliminary in vitro transwell cytotoxicity studies with PPGBC-56 and NIH 3T3 fibroblasts demonstrate that after $24 \mathrm{~h}$, minimal cytotoxicity is observed even at concentrations as high as $20 \mathrm{mg} /$ $\mathrm{mL}$ of terpolymer ( $>87 \%$ viability; Supplementary Fig. 15). In addition, the reported $\mathrm{LD}_{50} \mathrm{~s}$ of the degradation products butyric acid and glycerol are 3.7-9.8 g/kg (European Chemicals Agency) and $4.42 \mathrm{~g} / \mathrm{kg}$ in rabbits (National Library of Medicine: TOXNET), respectively. Similarly, exposure of RAW 264.7 macrophages to PPGBC-56 for $24 \mathrm{~h}$ affords an absence of the proinflammatory cytokine IL- 6 up to concentrations of $20 \mathrm{mg} /$ $\mathrm{mL}$, as the expressed cytokine IL-6 levels are comparable to the negative control (Supplementary Fig. 16).

In conclusion, we synthesized a series of polycarbonate terpolymers using a cobalt(III) salen catalyst in high turnover frequency, high polymer selectivity, moderate molecular weight, and low dispersity. Being composed of building blocks known to be on the GRAS list, present in foods, or our atmosphere, these terpolymers are attractive materials for potential commercial use from both environmental and biomedical perspectives. Of the synthesized polymers, PPGBC-56 exhibits stronger adhesion than commercial Scotch-tape ${ }^{\circledR}$ and comparable adhesion to Ducttape ${ }^{\circledast}$. Furthermore, this adhesive sticks to a variety of chemically distinct materials. At $20^{\circ} \mathrm{C}$, increased applied pressure yields greater tack strength force. This dependency is absent at a high temperature of $37^{\circ} \mathrm{C}$, and the adhesive itself is able to wet and subsequently bond surfaces with minimal applied contact force and time. The high viscosity of the adhesive at room temperature enables a thermoresponsive temperature trigger of adhesion to induce bonding and debonding. Through judicious choice of polymer with an eco design, our approach will open new avenues of research as well as catalyze the investigation of unique functional adhesive materials to meet the ever-increasing demands from society.

\section{Methods}

General information. All manipulations involving air- and/or water-sensitive compounds were carried out in a glovebox. All oxiranyl monomers were refluxed over $\mathrm{CaH}_{2}$, and fractionally distilled under a nitrogen atmosphere prior to use. Carbon dioxide $(99.995 \%$, bone dry) was purchased from Airgas and used as received. Reagents were purchased from Sigma-Aldrich and used as received. All measurements were taken from distinct samples.

Materials characterization. The characterization and synthesis of all compounds are described in full detail in the Supplementary Information (Supplementary Figs. 1-7). Materials previously synthesized and characterized are provided with references to the original work.

NMR experiments. ${ }^{1} \mathrm{H}$ and ${ }^{13} \mathrm{C}$ NMR spectra were recorded on a Varian $500 \mathrm{MHz}$ type $\left({ }^{1} \mathrm{H}, 500 \mathrm{MHz} ;{ }^{13} \mathrm{C}, 125 \mathrm{MHz}\right)$ spectrometer. Their peak frequencies were referenced against the solvent, chloroform- $\mathrm{d}$ at $\delta 7.24$ for ${ }^{1} \mathrm{H}$ NMR and $\delta 77.23$ ppm for ${ }^{13} \mathrm{C}$ NMR, respectively. 
Gel permeation chromatography. All polymer molecular weights were determined by gel permeation chromatography versus polystyrene standards (Agilent Technologies) using THF as the eluent at a flow rate of $1.0 \mathrm{~mL} / \mathrm{min}$ through a Styragel column (HR4E THF, $7.8 \times 300 \mathrm{~mm}$ ) with a Waters 2414 refractive index detector

MALDI-ToF. MALDI-ToF mass values for polymers were determined using a Bruker autoflex Speed MALDI-ToF mass spectrometer equipped with a SMARTbeam II and a flash detector. Samples were prepared by dissolving in a 1:1 vol/vol mixture of matrix solvent $(10 \mathrm{mg} / \mathrm{mL}$ solution of dithranol in THF with $0.1 \%$ AgTFA) and $10 \mathrm{mg}$ polymer dissolved in minimal amount THF.

DSC. The thermal properties of the polymers were measured by DSC using a TA Q100 under a nitrogen atmosphere (nitrogen flow rate: $60 \mathrm{~mL} \mathrm{~min}^{-1}$ ). All samples were tested at a heating rate of $10^{\circ} \mathrm{C} / \mathrm{min}$ and a cooling rate of $10^{\circ} \mathrm{C} / \mathrm{min}$ from -40 to $80^{\circ} \mathrm{C}$. The weight of all samples was between 2 and $10 \mathrm{mg}$ and the samples underwent three heat-cool-heat cycles. The glass transition temperature, $\mathrm{Tg}$, was noted in the DSC-thermogram as the midpoint temperature of the glass transition peak in the second heating cycle (Supplementary Fig. 9).

$180^{\circ}$ peel strength. The peel adhesion test was carried out at room temperature $\left(22^{\circ} \mathrm{C}\right)$ by using Fischerbrand glass microscope $\left(\mathrm{SiO}_{2}\right)$ slides (base stock) and a $\mathrm{A} 4$ paper (face stock) as substrates. (Supplementary Fig. 11).

The face dimensions for the glass slides were $7.6 \times 2.6 \mathrm{~cm}$. The adhesive was coated on the nonfrosted surface of the glass plate containing a coating area of $2 \times$ $2.6 \mathrm{~cm}$ with a coating thickness of $\sim 30 \mu \mathrm{m}$. Then, the paper substrate was stuck on the coated glass slide with moderate human finger pressure. The sample was let to settle for $1 \mathrm{~min}$ prior to testing on an Intron 5944 with peel speed operating at $360 \mathrm{~mm} / \mathrm{min}$.

Commercial all-purpose Duct Tape ${ }^{\circledast}$ (3M 2929) and Scotch Tape ${ }^{\circledast}$ (3M 810) were used as received, (besides width modifications) and stuck to the glass. Duct tape was cut to $2.6 \mathrm{~cm}$ of width, scotch tape was not modified. Three separate specimens were used for each adhesive formulation in this test. The average peak from the load propagation graph was used to calculate the peeling force. Peel strength is defined as the average load per width of the bondline required to separate progressively a flexible member from a rigid member (ASTM D 903).

Probe tack. All tack testing were performed on a Discovery Hybrid Rheometer (DHR-2 series) with $8 \mathrm{~mm}$ stainless steel-sand blasted parallel plate geometry with a Peltier plate. The adhesive was placed on the bottom plate and a top probe moving at $100 \mu \mathrm{m} / \mathrm{s}$ rested on the adhesive until the desired axial force was reached. After $5 \mathrm{~s}$, the top probe pulled away at a rate of $100 \mu \mathrm{m} / \mathrm{s}$ (Supplementary Fig. 12a and $\mathrm{b}$ ). The peak of the force curve is defined as the tack strength $\left(T_{\mathrm{s}}\right)$ and the area under the curve is defined as the tack energy $\left(T_{\mathrm{e}}\right)$ as calculated by Eq. (1), where $A$ denotes the surface area $\left(\mathrm{m}^{2}\right)$ of the probe, $r$ is the rate of probe separation in debonding $(\mathrm{m} / \mathrm{s}), F$ is the force $(\mathrm{N})$ measured during debonding, and $t$ is the time in seconds;

$$
T_{e}=2 x\left[\frac{r}{A} \int_{\mathrm{ti}}^{\mathrm{tf}} F(t) d t\right]
$$

Frequency sweeps. All oscillatory sweeps were performed on a Discovery Hybrid Rheometer (DHR-2 series) with $8 \mathrm{~mm}$ stainless steel parallel plate geometry with a gap size of $50 \mu \mathrm{m}$. Frequency sweeps were performed from 0.1 to $100 \mathrm{rad} / \mathrm{s}$ or 1 to $500 \mathrm{rad} / \mathrm{s}$ at $1 \%$ strain (determined to be in the linear viscoelastic region with a previous strain sweep) at specified temperatures $\left(20,25,37\right.$, and $\left.50^{\circ} \mathrm{C}\right)$ controlled by a Peltier plate. (Supplementary Fig. 14).

Cell culture. NIH 3T3 murine fibroblasts (ATCC) were cultured in Dulbecco's modified Eagle's medium supplemented with $10 \%$ bovine calf serum and $1 \%$ penicillin-streptomycin. RAW 264.7 murine macrophages were cultured in Dulbecco's modified Eagle's medium supplemented with $10 \%$ fetal bovine serum and $1 \%$ penicillin-streptomycin. Cells were maintained in a sterile, humidified environment at $37^{\circ} \mathrm{C}$ with $5 \% \mathrm{CO}_{2}$.

In vitro evaluation of cytotoxicity. NIH 3T3 cells were seeded in a 96-well plate at a density of 20,000 cells/well and were allowed to adhere for $24 \mathrm{~h}$. The media was then replaced with fresh media, and cells were incubated with polymer samples in $5 \%$ DMSO using transwell inserts $(0.4 \mu \mathrm{m}$ pores). Cell viability was assessed $24 \mathrm{~h}$ after treatment via the MTS in vitro cytotoxicity assay (CellTiter 96 Aqueous One, Promega). The average of two experiments $(n=2)$ in which $n=6$ per polymer concentration.

In vitro evaluation of immunogenicity. RAW 264.7 cells were seeded in a 96-well plate at a density of 30,000 cells/well and were allowed to adhere for $24 \mathrm{~h}$. The media was then replaced with fresh media, and cells were incubated with polymer samples in 5\% DMSO using transwell inserts $(0.4 \mu \mathrm{m}$ pores). IL- 6 levels were measured via ELISA kit (Abcam) and compared with those of RAW 264.7 treated with lipopolysaccharide-a molecule known to stimulate IL-6 production and immunogenicity in vitro $(n=6)$.

Reporting summary. Further information on research design is available in the Nature Research Reporting Summary linked to this article.

\section{Data availability}

The data supporting this article are found within the text and the supplementary information file. The source data underlying Figs. 2a, 3a-d, and Supplementary Fig. 12 are provided as a Source Data file (https://doi.org/10.6084/m9.figshare.10013315). Any additional data is available from the corresponding author upon request.

Received: 6 June 2019; Accepted: 7 November 2019;

Published online: 02 December 2019

\section{References}

1. Benedek, I. Pressure-Sensitive Adhesives and Applications (Marcel Dekker Inc., 2010).

2. Khan, I. \& Poh, B. T. Natural rubber-based pressure-sensitive adhesives: a review. J. Polym. Environ. 19, 793-811 (2011).

3. Sasaki, M. et al. The effect of tackifier on phase structure and peel adhesion of a triblock copolymer pressure-sensitive adhesive. Int. J. Adhes. Adhes. 28, 372-381 (2008).

4. Nakamura, Y. et al. Tack and viscoelastic properties of an acrylic block copolymer/tackifier system. Int. J. Adhes. Adhes. 29, 806-811 (2009).

5. Felton, L. A., Austin-Forbes, T. \& Moore, T. A. Influence of surfactants in aqueous-based polymeric dispersions on the thermomechanical and adhesive properties of acrylic films. Drug Dev. Ind. Pharm. 26, 205-210 (2000).

6. Tic, W. \& Guziałowska-Tic, J. Properties of a PVAc emulsion adhesive using a nonphthalate plasticizer obtained by condensation of 2-methylpropanal. J. Adhes. Sci. Technol. 32, 1861-1875 (2018).

7. Mazzoni, A. et al. Cross-linking effect on dentin bond strength and MMPs activity. Dent. Mater. 34, 288-295 (2018).

8. Zhao, S. et al. Fully bio-based soybean adhesive in situ cross-linked by interactive network skeleton from plant oil-anchored fiber. Ind. Crops Prod. 122, 366-374 (2018).

9. Díaz, M. F., Barbosa, S. E. \& Capiati, N. J. Reactive compatibilization of PE/PS blends. Effect of copolymer chain length on interfacial adhesion and mechanical behavior. Polymer 48, 1058-1065 (2007).

10. Moyano, M. A., París, R. \& Martín-Martínez, J. M. Viscoelastic and adhesion properties of hot-melts made with blends of ethylene-co-n-butyl acrylate (EBA) and ethylene-co-vinyl acetate (EVA) copolymers. Int. J. Adhes. Adhes. 88, 34-42 (2019).

11. Zhao, Z. et al. Hot-melt pressure-sensitive adhesives based on SIS-g-PB copolymer for transdermal delivery of hydrophilic drugs. Int. J. Adhes. Adhes. 91, 72-76 (2019).

12. Anderson, K. S. \& Hillmyer, M. A. The influence of block copolymer microstructure on the toughness of compatibilized polylactide/polyethylene blends. Polymer 45, 8809-8823 (2004).

13. Shibano, T. Pressure sensitive-adhesive tapes or sheets. US Patent 4636432 (1987).

14. Kawabe, M., Tasaka, S. \& Inacaki, N. Effects of surface modification by oxygen plasma on peel adhesion of pressure-sensitive adhesive tapes. J. Appl. Polym. Sci. 78, 1392-1401 (2000).

15. Webster, I. Recent developments in pressure-sensitive adhesives for medical applications. Int. J. Adhes. Adhes. 17, 69-73 (1997).

16. Birkholz, R. B. Pressure sensitive adhesive label. US Patent 4,895,747 (1990)

17. Luhmann, B. Pressure sensitive adhesive hook. US Patent 5,409,189 (1995).

18. Sun, S., Li, M. \& Liu, A. A review on mechanical properties of pressure sensitive adhesives. Int. J. Adhes. Adhes. 41, 98-106 (2013).

19. Pulidindi, K. \& Chakraborty, S. Pressure sensitive adhesive market. Glob. Mark. Insights. Accessed 20 February 2019. https://www.gminsights.com/ pressrelease/pressure-sensitive-adhesives-market (2019).

20. Zhong, C. et al. Strong underwater adhesives made by self-assembling multiprotein nanofibres. Nat. Nanotechnol. 9, 858-866 (2014).

21. Hamilton, W. et al. Adhesive force of a single gecko foot-hair. Nature 405, 671-702 (2000).

22. Baik, S., Lee, H. J., Kim, D. W., Kim, J. W. \& Lee, Y. Bioinspired adhesive architectures: from skin patch to integrated bioelectronics. Adv. Mater. 31 $1-18$ (2019)

23. Del Campo, A., Greiner, C., Álvarez, I. \& Arzt, E. Patterned surfaces with pillars with controlled 3D tip geometry mimicking bioattachment devices. Adv. Mater. 19, 1973-1977 (2007). 
24. Zhou, M., Pesika, N., Zeng, H., Tian, Y. \& Israelachvili, J. Recent advances in gecko adhesion and friction mechanisms and development of gecko-inspired dry adhesive surfaces. Friction 1, 114-129 (2013).

25. Lee, H., Lee, B. P. \& Messersmith, P. B. A reversible wet/dry adhesive inspired by mussels and geckos. Nature 448, 338-341 (2007).

26. Zhao, Y. et al. Bio-inspired reversible underwater adhesive. Nat. Commun. 8, 1-8 (2017)

27. Schneider, T. \& Budisa, N. Expanding the DOPA universe by genetically encoded, mussel-inspired bioadhesives for material sciences and medicine. ChemBioChem 20, 2163-2190 (2019).

28. Li, W. et al. Enhanced adhesion of carbon nanotubes by dopamine modification. Langmuir 35, 4527-4533 (2019).

29. Ahn, B. K. Perspectives on Mussel-inspired wet adhesion. J. Am. Chem. Soc. 139, 10166-10171 (2017).

30. Lin, Q. et al. Adhesion mechanisms of the mussel foot proteins mfp-1 and mfp-3. Proc. Natl Acad. Sci. 104, 3782-3786 (2007).

31. Ricapito, N. G., Ghobril, C., Zhang, H., Grinstaff, M. W. \& Putnam, D. Synthetic biomaterials from metabolically derived synthons. Chem. Rev. 116, 2664-2704 (2016).

32. Zhang, X., Fevre, M., Jones, G. O. \& Waymouth, R. M. Catalysis as an enabling science for sustainable polymers. Chem. Rev. 118, 839-885 (2017)

33. Gross, R. A. \& Kalra, B. Biodegradable polymers for the environment. Science 297, 803-807 (2002)

34. Inoue, S., Koinuma, H. \& Tsuruta, T. Copolymerization of carbon dioxide and epoxide. J. Polym. Sci. Part B Polym. Lett. 7, 287-292 (1969).

35. Qin, Z., Thomas, C. M., Lee, S. \& Coates, G. W. Cobalt-based complexes for the copolymerization of propylene oxide and $\mathrm{CO}_{2}$ : active and selective catalysts for polycarbonate synthesis. Angew. Chem. Int. Ed. 42, 5484-5487 (2003).

36. Lu, X. B. \& Darensbourg, D. J. Cobalt catalysts for the coupling of $\mathrm{CO}_{2}$ and epoxides to provide polycarbonates and cyclic carbonates. Chem. Soc. Rev. 41, 1462-1484 (2012).

37. Ren, W. M. et al. Highly active, bifunctional Co(III)-salen catalyst for alternating copolymerization of $\mathrm{CO}_{2}$ with cyclohexene oxide and terpolymerization with aliphatic epoxides. Macromolecules 43, 1396-1402 (2010).

38. Ren, W. M., Liu, Z. W., Wen, Y. Q., Zhang, R. \& Lu, X. B. Mechanistic aspects of the copolymerization of $\mathrm{CO}_{2}$ with epoxides using a thermally stable singlesite cobalt(III) catalyst. J. Am. Chem. Soc. 131, 11509-11518 (2009).

39. Taherimehr, M. \& Pescarmona, P. P. Green polycarbonates prepared by the copolymerization of $\mathrm{CO}_{2}$ with epoxides. J. Appl. Polym. Sci. 131, 1-17 (2014).

40. Beharaj, A., Ekladious, I. \& Grinstaff, M. W. Poly(Alkyl glycidate carbonate)s as degradable pressure-sensitive adhesives. Angew. Chem. Int. Ed. 58, 1407-1411 (2019).

41. Zhang, H., Lin, X., Chin, S. \& Grinstaff, M. W. Degradable analogue of poly (acrylic acid). J. Am. Chem. Soc. 137, 12660-12666 (2015).

42. Zhang, H. \& Grinstaff, M. W. Synthesis of atactic and isotactic poly(1,2glycerol carbonate)s: degradable polymers for biomedical and pharmaceutical applications. J. Am. Chem. Soc. 135, 6806-6809 (2013).

43. U.S. National Library of Medicine. Glycerin. Toxicology Data Network. https:// toxnet.nlm.nih.gov/cgi-bin/sis/search/a?dbs+hsdb:@term+@DOCNO+492 (2019).
44. The European Union. Butryc Acid. European Chemicals Agency. https://echa. europa.eu/registration-dossier/-/registered-dossier/13507/7/3/4 (1954).

45. Saxby, M. J. A. Survey of chemicals causing taints and off-flavours in food. In Food Taints and off-Flavours (Springer, 1996).

\section{Acknowledgements}

This work was supported in part by the NSF (DMR-1410450 and DMR-1507081) and the BU Undergraduate Research Opportunities Program (UROP; EZM). NMR facilities at Boston University are supported by the NSF (CHE-0619339).

\section{Author contributions}

A.B. contributed to the synthesis of polymers, the adhesion measurements, and the analysis of data. E.Z.M. contributed to synthesis and characterization of the polymers. W. A.B. contributed to the in vitro experiments. A.B. and M.W.G. contributed to the experimental design and wrote the paper.

\section{Competing interests}

The authors declare no competing interests.

\section{Additional information}

Supplementary information is available for this paper at https://doi.org/10.1038/s41467019-13449-y.

Correspondence and requests for materials should be addressed to M.W.G.

Peer review information Nature Communications thanks the anonymous reviewers for their contribution to the peer review of this work. Peer reviewer reports are available.

Reprints and permission information is available at http://www.nature.com/reprints

Publisher's note Springer Nature remains neutral with regard to jurisdictional claims in published maps and institutional affiliations.

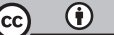

Open Access This article is licensed under a Creative Commons Attribution 4.0 International License, which permits use, sharing, adaptation, distribution and reproduction in any medium or format, as long as you give appropriate credit to the original author(s) and the source, provide a link to the Creative Commons license, and indicate if changes were made. The images or other third party material in this article are included in the article's Creative Commons license, unless indicated otherwise in a credit line to the material. If material is not included in the article's Creative Commons license and your intended use is not permitted by statutory regulation or exceeds the permitted use, you will need to obtain permission directly from the copyright holder. To view a copy of this license, visit http://creativecommons.org/ licenses/by/4.0/.

(C) The Author(s) 2019 